\title{
UNDERSTANDING TORSIONAL PHENOMENA IN DUCTILE SYSTEMS
}

\author{
Tom Paulay'
}

\begin{abstract}
Recent studies provided opportunities to review some of the principles, which have been used in the formulations of internationally accepted code-recommendations relevant to the seismic design of ductile buildings also subjected to torsional phenomena. With the progress of this study, features emerged which are considered to have contributed to a better understanding of structural behaviour. Moreover, the identification of deeply embedded fallacies, relevant to ductile response, suggested the introduction of some changes in seismic design strategies, yet not widely known or appreciated. Reasons for necessary re-interpretations of traditional structural properties, together with illustrative examples, demonstrating applications, rather than set code-type rules, are offered.
\end{abstract}

\section{INTRODUCTION}

A draft report on the assessment of the structural performance of existing buildings with earthquake risk [1] ushered in inquiries $[2,3,4]$ relevant to the torsional seismic response of ductile buildings. A question which the report [1] posed was: "For buildings where structural details are not available (documentation lost, etc), how could the displacement capacity of the structural system be assessed when its unquestionably affected by torsional phenomena?" By similarity to the concepts of the philosophy of capacity design, the establishment of ductile torsional mechanisms within the structural system, comprising lateral force-resisting elements, offered a promising starting point for further study [5]. Soon contradictions between existing code provisions, catering for torsional effects [6], and based on the response of elastic systems, and the needs for assessing displacements associated with inelastic seismic response and relevant limit states, emerged. As the study progressed some fallacies in traditional seismic design procedures needed to be rectified [7]. Consequent conclusions enabled ductile torsional phenomena to be better understood and more rational and promising design strategies to be conceived $[8,9]$. However, as in routine research work aiming at innovations, pitfalls were encountered. In the functioning of admissible torsional mechanisms, inadvertently the influence of mass rotations during dynamic response was neglected. Further studies [10, 11] lead to behaviour-based explanations of this specific torsional phenomenon, without being able as yet to arrive at a quantification of it, which would be simple and transparent enough for possible incorporation into routine design practice.

The motivation to introduce some new principles, relevant to inelastic structural response, was the perceived need to emphasize the importance of earthquake-induced displacements, rather than a particular method of assigning strength to elements of a system. Identification of structural behaviour, rationale and transparency of a viable design strategy, combined with simplicity in application, were central issues of this motivation.

Relevant code provisions $[6,12]$ are based on a manipulation of fallaciously defined stiffness eccentricities, leading to specific allocation of strength to elements. A more promising approach may be based on addressing directly the major cause of torsional phenomena, eccentricities. This is claimed to be primarily strength eccentricity, over which, as subsequent evidence will demonstrate, the designer has full control. It will also be seen that stiffness eccentricity is a function of strength eccentricity.

\section{DESIGN AIMS}

The primary purpose of this study was to address means by which performance criteria, conforming with the appropriate limit state, may be rationally executed. Therefore, attention is focused on earthquake-induced displacements in buildings with adequate strength. The aims are thus:

\footnotetext{
'Emeritus Professor, Department of Civil Engineering,

University of Canterbury (Life Member).
} 
" Earthquake-induced deformations, including system twist, should limit the expected displacement ductility demand on any element to its stipulated ductility capacity, $\mu_{\Delta \text { imax }}$.

"Magnitudes of ultimate interstorey displacements, to be expected at locations remote from the centre of mass, should not exceed those considered acceptable for the building, typically $2-2.5 \%$ of the storey height.

" Performance criteria may require displacements associated with a specific limit state, to be less than those allowed by the limits listed above.

The purpose of considering torsion in ductile systems should be, therefore, to account for twist-induced displacements of certain elements, i.e., displacements additional to that associated with uniform system translation, rather than to provide torsional resistance. The word "twist" is used deliberately to emphasize the need to address torsion-induced displacements. Details set out subsequently should enable designers to quantify displacements relevant to the above design aims.

\section{TERMINOLOGY USED}

"In this study of earthquake-induced displacements of buildings, reference will be made to the structural system.

" A structural system comprises lateral force-resisting elements generally arranged in two orthogonal directions. Due to torsional effects elements of the system may be subject to difference displacements. Typical elements are bents of ductile frames or interconnected walls in the same plane.

"A lateral force-resisting element may comprise several components. The components will, however, be subjected to identical displacements. Typical components are beams or columns, beam-column sub-assemblages or individual walls.

Figure 1 illustrates typical elements and components of an example structural system. In the technical literature the terms component and element are often used to describe the same part of a system. Distinct differentiation between component and element behaviour is made in this study.

\section{FUNDAMENTAL PROPERTIES OF STRUCTURAL COMPONENTS}

\subsection{Definitions}

Three important structural properties, strength, yield displacement and stiffness, will be considered separately for individual components, elements comprising components, and the entire structural system.

Three important and familiar locations in the plan of a building, the centre of rigidity or stiffness, the centre of strength or resistance and the centre of the distributed mass, will be subsequently abbreviated as $\mathrm{CR}, \mathrm{CV}$ and $\mathrm{CM}$, respectively. (Figure 10).

Unless otherwise stated in the text, ductility imposed on components or elements of the structural system relates to lateral displacements. These displacements, associated with a particular mechanism, must be compatible with each other.
As a general rule, the magnitudes of displacement ductilities relevant to components, elements and the system will be different.

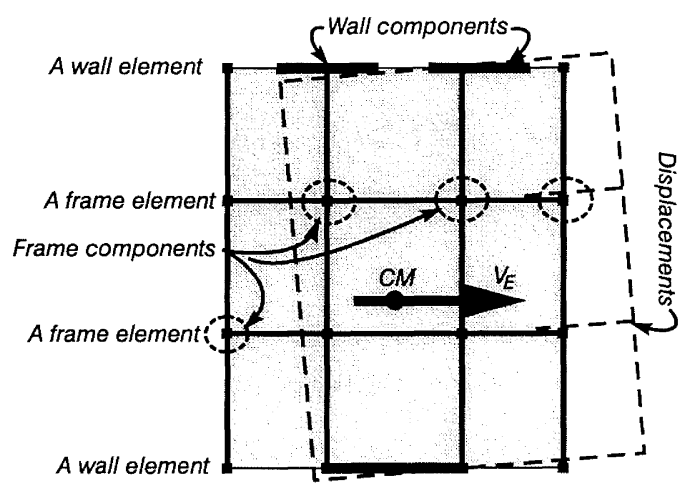

Plan of a building system

Figure 1: Nomenclature

The term "strength" defines the base or storey shear capacity, consistent with the nominal flexural strength of the critical section or sections of components. To facilitate insight, when necessary, some previously published $[8,11]$ concepts are restated here.

Only single mass systems are considered in this study.

\subsection{Bi-linear Force-displacement Modelling}

In agreement with commonly used modelling practice, it is considered that for purposes of seismic design, the bi-linear replacement of the non-linear force- displacement response of a system and its constituent elements and components, is entirely acceptable. Figure 2 presents this familiar simulation for a steel(s) and reinforced concrete(c) component. It is thus seen that stiffness is defined as the ratio of nominal strength, $\mathrm{V}_{\mathrm{ni}}$, of the component to its yield displacement, $\Delta_{\mathrm{yi}}$, i.e.,

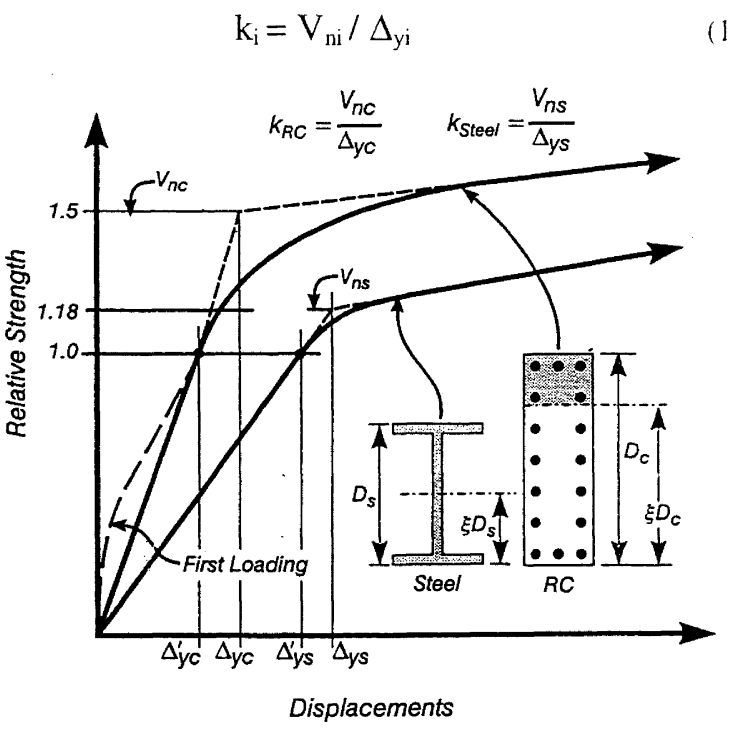

Figure 2: $\quad$ Bi-linear idealization of force-displacement responses. 
Because of widespread unintentional misuse, the correct interpretation of this very fundamental relation is of great importance.

The nominal yield displacement, $\Delta_{\mathrm{yi}}$ or $\Delta_{\mathrm{y}}$, being a function of the yield curvature, depends only on the geometry of the component and the properties of the material used [13] (Section 4.3) Contrary to traditional definitions, it is independent of strength! The nominal strength of an element, $\mathrm{V}_{\mathrm{nc}}$ or $\mathrm{V}_{\mathrm{ns}}$ on the other hand, as will be postulated subsequently, is the choice of the designer. It is dictated only by the requirements of equilibrium and the specified seismic resistance to be provided for the system. Therefore, contrary to the widely used practice of researchers carrying out parametric analytic studies, component stiffness in such studies should never be chosen as an independent variable. It is restated that the strength of an element must be known before its stiffness can be quantified. These principles are essential also for the understanding of torsional phenomena. Therefore, the application of these elementary, yet generally unappreciated, relationships will be extensively illustrated.

\subsection{Yield Curvature}

Inelastic displacements of components of structures exposed to ductility demands originate predominantly from plastic hinges in these components. Such displacements are directly related to curvatures within the plastic hinge regions. The relationship between yield curvature and corresponding yield displacement of a component is well established [13]. For this purpose of bi-linear moment-curvature relationships, two pairs of simple quantities need to be determined. The first pair is the magnitude of the bending moment, $M_{y}$, and the curvature, $\phi_{y}^{\prime}$, associated with the onset of yielding of the material at one or both extreme fibres of the relevant section. Up to this level of actions a linear relationship may be assumed. The curvature at the onset of yielding is simply

$$
\phi_{\mathrm{y}}^{\prime}=\varepsilon_{\mathrm{y}} / \xi \mathrm{D}
$$

where $\xi D$ is the distance of the yielding fibre from the neutral axis of the section with an overall depth of D (Figure 2). Typical values of $\xi$ are shown for some example sections in Figure 3.

The other pair of quantities is the nominal flexural strength of the critical section, $M_{n}$, which then enables, by linear extrapolation, the determination of the nominal yield curvature, $\phi_{\mathrm{y}}$, thus

$\phi_{\mathrm{y}}=\left(\mathrm{M}_{\mathrm{n}} / \mathrm{M}_{\mathrm{y}}\right) \phi_{\mathrm{y}}^{\prime}=\left[\left(\mathrm{M}_{\mathrm{n}} / \mathrm{M}_{\mathrm{y}}\right) / \xi\right]\left(\varepsilon_{\mathrm{y}} / \mathrm{D}\right)=\psi \varepsilon_{\mathrm{y}} / \mathrm{D}$

These quantities may be routinely defined [14]. Typical values which may be used for seismic design, are presented in Fig. 3. The equivalent uniformly distributed concrete compression stress for components 5 to 8 in Fig. 3 is denoted $\mathrm{f}_{\mathrm{c}}{ }^{*}$. Values of $\psi$ are not exact, but are satisfactory for the use in seismic design.

The simple relationships presented here are applicable to homogeneous (steel) as well as composite (reinforced concrete) sections.

Once the nominal yield curvatures at critical sections of components are known, the relevant nominal yield displacements of those components are readily established. This may be achieved by replacing [13], for example in computer programs, the traditionally defined curvature at the critical section, $\phi=\mathrm{M}_{\max } / \mathrm{EI}$, by the nominal yield curvature, given by Eqn.(3) and in Fig. 3. Therefore, for the replacement of the flexural rigidity of the critical section, EI its nominal flexural strength, $\mathbf{M}_{\mathrm{n}}$, must be known. This replacement may be achieved in routine analyses by using the equivalent second moment of area, $I_{e}$, of the section of prismatic members, defined by

$$
\mathrm{I}_{\mathrm{e}}=\left[\mathrm{M}_{\mathrm{n}} /\left(\phi_{\mathrm{y}} \mathrm{E}_{\mathrm{c}} \mathrm{I}_{\mathrm{g}}\right)\right] \mathrm{I}_{\mathrm{g}}
$$

where $E_{c}$ is the modulus of elasticity of the concrete and $I_{g}$ is the second moment of the gross concrete area.

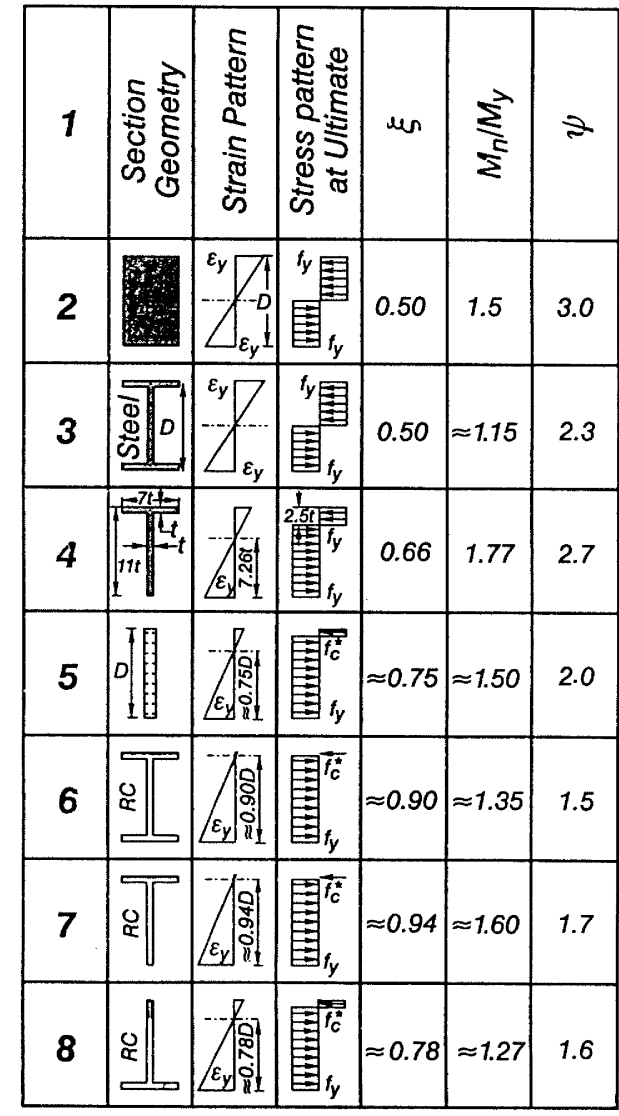

Figure 3: Parameters defining the nominal yield curvature for typical example sections.

\subsection{Component Nominal Yield Displacement}

Once the nominal yield curvature at the critical section of a component has been established (Eqn.(3)), the corresponding nominal yield deflection, $\Delta_{\mathrm{yi}}$, at the relevant level may be readily established. For example for the top of a cantilever wall component shown in Fig. 4, it is

$$
\Delta_{\mathrm{yi}}=C \phi_{y i} h_{w i}^{2}
$$

where $\mathrm{C}$ is a coefficient which quantifies the distribution pattern of the lateral forces, and $h_{w i}$ is the height of the wall component. For example for the triangular force pattern, 
seen in Fig. 4, $C=11 / 60$. Therefore, with the estimation of the yield curvature from Eqn.(3), it is found that the nominal yield displacement at the top of a rectangular cantilever wall with $\psi=2$ may be approximated by

$$
\Delta_{\mathrm{yi}}=0.55 \varepsilon_{y} h_{w i}^{2} / l_{w i}
$$

In buildings the heights of the wall components are generally identical. Therefore, for these components the yield displacements are simply inversely proportional to the lengths of the walls. This relative value,

$$
\Delta_{\mathrm{yi}} \propto 1 / 1_{\mathrm{wi}}
$$

can often be used to evaluate relative displacements and hence applicable displacement ductilities. Subsequent examples will illustrate this.

When necessary additional terms of deformations, for example those due to shear, slip at anchorages and distortions of beam-column joints [15], may need to be added to those due to flexure alone.

\subsection{Stiffness}

\subsubsection{Component stiffness}

With the aid of Fig. 2 the stiffness of a component was defined by Eqn.(1). Once again it is emphasized that for bilinear modelling of behaviour, the nominal strength of the component must be known and its geometry-dependent nominal yield displacement must be defined. The displacements associated with the onset of yielding, i.e., $\phi_{y}^{\prime}$, are shown with distinct dots in Fig. 2. These indicate the (normalized) yield strength of the components. These levels of strength should be considered when checking serviceability limit state criteria.

\subsubsection{Element stiffness}

It was stated in Section 3 that an element may comprise a number of interconnected components subjected to identical lateral displacements. As subsequent examples will illustrate (Fig. 4), it is adequate to assume that the stiffness of an element is the sum of the stiffness of its constituent components.

Based on bi-linear modelling the knowledge of component properties enables the nominal yield displacement of the element to be defined as

$$
\Delta_{\mathrm{ye}}=\sum \mathrm{V}_{\mathrm{ni}} / \sum \mathrm{k}_{\mathrm{i}}
$$

\subsubsection{System stiffness}

By similarity the stiffness of a system may be approximated by the sum of the element stiffness. System stiffness so defined relates to translation of the system without any twist. A system comprising elements with different yield displacements, such as illustrated in Fig. 17, does not have a unique yield point. As examples will illustrate, a bi-linear modelling of the system response overcomes this apparent difficulty.

\subsection{Assignment of Strength}

It has been postulated $(10,11)$ that, because yield displacements (Eqn.(5)) are independent of the strength of components, strength to these may be assigned arbitrarily. This fact provides the designer with much greater freedom in beneficially influencing structural response, than when using traditional techniques in which the design strength of a component was made proportional to its traditional geometry-based stiffness. Several examples will be presented to illustrate the perceptive use of this freedom.

\section{THE MODELLING OF LATERAL FORCE-RESISTING ELEMENTS}

The design base shear for a ductile system is resisted in both principal directions by a number of, generally parallel, lateral force resisting elements. These were defined in Section 3. Typical examples presented here are interacting cantilever walls, continuous frames arranged in bents with the prime role of carrying gravity loads, and interconnected ductile columns with constant or variable heights carrying a rigid superstructure. The contribution of such elements to the behaviour of a building system during ductile seismic response, when interconnected by an infinitely rigid floor diaphragm, is the subject of this study. Typical elements are subsequently illustrated and examined.

\subsection{Interconnected Cantilever Wall Components of Identical Heights}

The example structure, illustrated in Figure 4 and extensively used in other publications [11], summarizes the conclusions drawn from the postulates made in Section 4. Figure 5 compares model responses based on two different ways of assigning strength to constituent components. Note that the 4 wall components of this lateral force-resisting element of a system are subjected to identical lateral displacements.

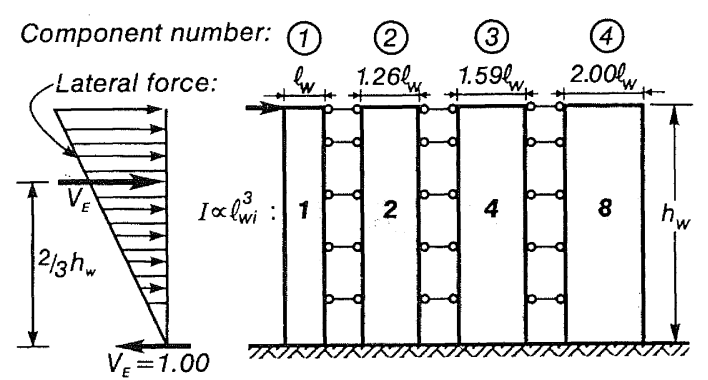

Figure 4: Interconnected cantilever wall components.

Traditional techniques, based on stiffness being proportional to the flexural rigidity of the component, suggest that component strengths should bear the proportions of 1:2:4:8. Traditional assumptions imply that these strengths, $V_{i c}$, are developed at element displacements, $\Delta$. It is then traditionally and fallaciously assumed that, having attained these strengths, all elements will commence yielding simultaneously. However, as Eqn. (6) and Fig. 2 demonstrated, irrespective of the strength of a component, its nominal yielding will commence at its geometry-dependent yield displacement. 
Figure 5(a) presents the bi-linear modeling of the components as well as that of the lateral force resisting element shown in Figure 4. Relative yield displacements (Eqn.(7)), given in Table 1, are normalized in terms of that of component (1). In accordance with Section 4.5.2, the summation of component stiffness, corresponding with the conventional assignment of relative strengths, $V_{i c}$, resulted in the element stiffness, $\sum \mathrm{k}_{\mathrm{i}}=1.725$. This enables the nominal element yield displacement, $\Delta_{y c}=1 / 1.725=0.58$, shown in Fig. 5(a), to be determined. These then are the properties of this element with unit strength, which will need to be considered with those of similar parallel elements when considering inelastic translational and torsion-induced displacements of the entire system.

As an example, it is assumed that the displacement ductility capacity of the appropriately detailed [16] wall components of the structure in Fig. 4 is $\mu_{\Delta \text { imax }}=5$. Therefore, the displacement demand imposed on this element must be limited to the capacity of component (4) with the smallest yield displacement. This is $\Delta_{\mathrm{uc}}=\mu_{\Delta 4} \Delta_{\mathrm{y} 4}=5 \times 0.5=2.5$ displacement units. The corresponding displacement ductility capacity of the 4-component element is thus, as shown in Fig. 5(a), $\mu_{10}=\Delta_{\mathrm{uc}} / \Delta_{\mathrm{yc}}=2.5 / 0.58=4.31$

As the example in Fig. (17) will show, when the components of the structure in Fig. 4 become elements of a system, this type of strength distribution would lead to undesirable excessive eccentricities.

The designer may then use judgement guided by design intentions, to embark on an arbitrary assignment of strengths. Such an arbitrary choice of relative component strengths, $V_{\text {ia }}$, is shown in column 5 of Table 1. These may be compared with those derived in accordance with conventional procedures, $V_{i c}$, recorded in column 3 of Table 1 . It is seen that the difference of stiffness of the two elements is small. Effects of the particular choice of strength, $V_{i a}$, will be subsequently examined in Section 7.7.

Table 1: Properties of the Structures in Figs. 4 \& 5

\begin{tabular}{|c|c||c|c||c|c|}
\hline 1 & 2 & 3 & 4 & 5 & 6 \\
\hline & $\Delta_{\mathrm{yi}}$ & $\mathrm{V}_{\mathrm{ic}}$ & $\mathrm{k}_{\mathrm{ic}}$ & $\mathrm{V}_{\mathrm{ia}}$ & $\mathrm{k}_{\mathrm{i} \mathrm{i}}$ \\
\hline No. & \multicolumn{1}{|c||}{} & \multicolumn{2}{|c|}{ Conventional } & \multicolumn{2}{|c|}{ Arbitrary } \\
\hline 1 & 1.000 & 0.067 & 0.067 & 0.133 & 0.133 \\
2 & 0.794 & 0.133 & 0.168 & 0.266 & 0.335 \\
3 & 0.629 & 0.267 & 0.424 & 0.365 & 0.580 \\
4 & 0.500 & 0.533 & 1.066 & 0.236 & 0.472 \\
\hline$\sum$ & - & 1.000 & 1.725 & 1.000 & 1.520 \\
\hline
\end{tabular}

The bi-linear simulation of component and element behaviour corresponding to strength distribution shown in column 5 of Table 1 is presented in Fig. 5(b). From Eqn.(5) the nominal yield displacements of the two models, (Fig. 5) are found to be $\Delta_{\mathrm{yc}}=1 / 1.725=0.58$ and $\Delta_{\mathrm{ye}}=1 / 1.52=0.66$, respectively. Consequently the displacement ductility demand on the system represented by Figure 5(b) must be reduced to $\mu_{\Delta}=2.5 / 0.66=3.79$

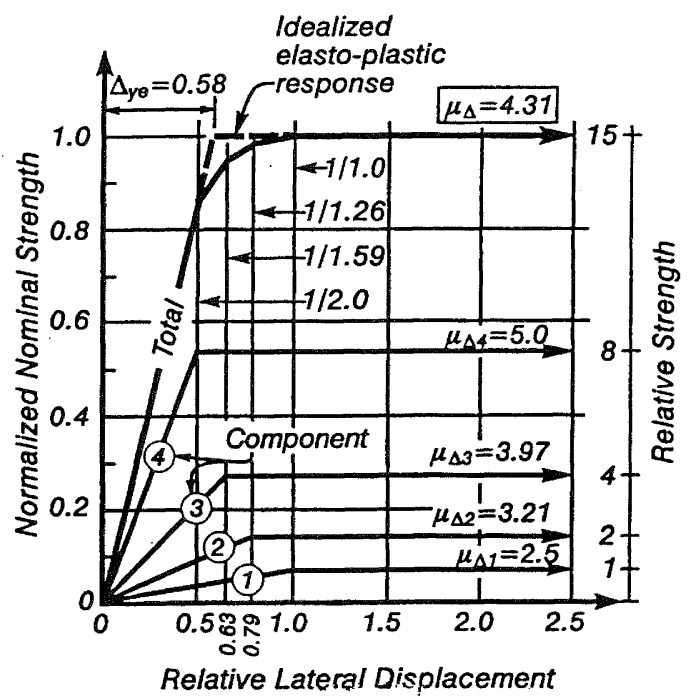

(a) Traditional Strength Distribution

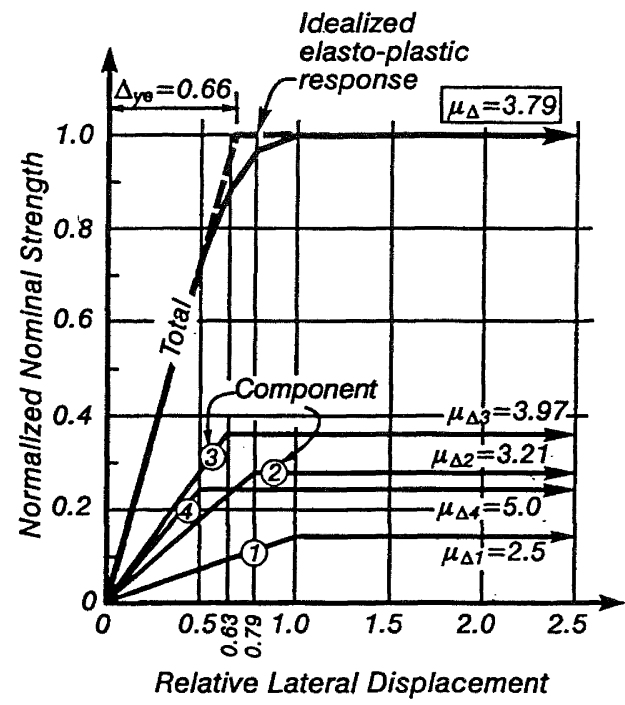

(b). An Arbitrary Strength Distribution

Figure 5: Idealized force-displacement relationships for an element with wall components.

\subsection{A Structure Supported by Columns with Variable Heights}

To illustrate the advantageous application of these simple principles, and to illuminate inappropriate conclusions that traditional usage of the theory of elasticity might lead to, another idealized example element, shown in Fig. 6, is considered. The inertia force, $V_{E}$, generated in a rigid superstructure needs to be transmitted via 5 columns of 
identical cross sections but different heights. Because of the identical depths of the columns, the nominal yield curvatures, $\phi_{y}$, will also be close to identical (Eqn.(3)). The yield displacements are $\Delta_{\mathrm{yi}}=\phi_{\mathrm{y}} \mathrm{h}_{\mathrm{i}}{ }^{2} / 6$. They are thus proportional to the square of the column heights $h_{i}$. According to conventional usage, shear forces should be assigned to the columns in proportion to traditionally defined shear stiffness, i.e., $1 / \mathrm{h}_{\mathrm{i}}{ }^{3}$. The normalized values so obtained are shown in column 4 of Table 2. The corresponding relative values of the design bending moments at both ends of columns, $\mathrm{M}_{\mathrm{i}}=0.5 \mathrm{~V}_{\mathrm{i}} \mathrm{h}_{\mathrm{i}}$, are shown in column 6 of the table. As expected, the design shear force in component (1) is 8 times that in component (5).

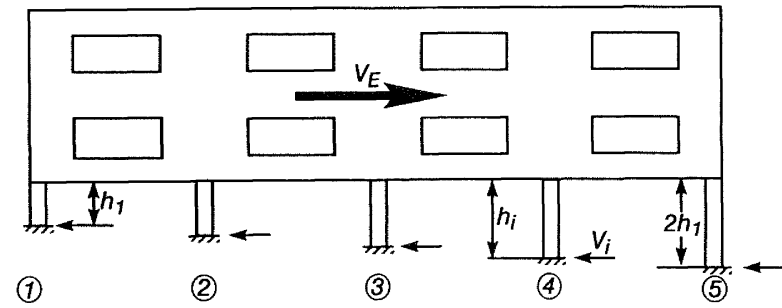

Figure 6: A structure supported on columns with variable heights.

As stated in Section 4.6, as long as equilibrium criteria are not violated, the designer has a free choice in the assignment to columns of strength. One arbitrary but appealing approach would be to utilize columns with identical flexural strengths,

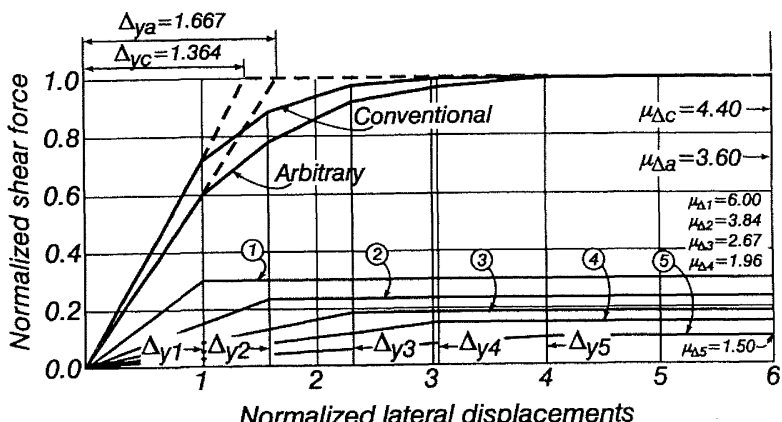

Figure 7: Force-displacement modelling of the element shown in Figure 6. i.e., approximately identical vertical reinforcement. This would lead to the assignment of lateral forces inversely proportional to the heights of the components. The corresponding normalized arbitrary forces and design moments are shown in columns 7 and 9 of Table 2 . It is seen that in this case the differences in shear demands on the five columns are quite moderate. Moreover, the maximum shear, $\mathrm{V}_{1}$, a quantity likely to be critical, is reduced to $60 \%$ of that in the previous case.

Figure 7 shows negligible differences in the force-displacement relationships for the element designed in two different ways. Using Eqn.(8) and the data in columns 5 and 8 of Table 2, the element nominal yield displacements for the two variants are readily established. These are shown as $\Delta_{\mathrm{yc}}=1 / 0.733=1.364$ and $\Delta_{\mathrm{ya}}=1 / 0.6=1.667$ in Fig. 7 . The ultimate element displacement must not exceed the displacement capacity of the critical component (1), assumed in this example to be $6 \times \Delta_{y 1}=6$ units. Therefore, element displacement ductility demands must be restricted to $\mu_{\Delta c} \leq$ $6 / 1.364=4.40$ or $\mu_{\Delta \mathrm{a}}=6 / 1.667=3.60$, respectively Features of the findings worth noting are:

" The sequence in the onset of yielding in the 5 columns, in this case from (1) to (5), is independent of the allocation of element strengths.

"In terms of the precision expected in seismic design, the differences in element stiffness and hence element ductility capacities are negligible. The periods of vibration of the elastic "arbitrary" element would be some $10 \%$ smaller than that of the "conventional" element.

" The implication of the traditional allocation of strengths and the associated assumption $[12,16]$ that the ductility capacity of a frame element may be $\mu_{\Delta}=6$, would lead to a serious underestimation of the ductility demand on the critical columns ( 1 ) and (2).

" The ease with detailing of the reinforcement and the significant reduction of the shear demand on the shortest column, are benefits obtained from this choice of strength allocation to components.

" Irrespective of flexural strength, the yield displacement of column (5) is 4 times that of column (1).

Table 2: Data for the example structure in Fig. 6

\begin{tabular}{|c|c|c||c|c|c||c|c|c|}
\hline \multicolumn{3}{|c||}{ Properties } & \multicolumn{3}{c||}{ Conventional } & \multicolumn{3}{c|}{ Arbitrary } \\
\hline 1 & 2 & 3 & 4 & 5 & 6 & 7 & 8 & 9 \\
\hline No. & $\mathrm{h}_{\mathrm{i}}$ & $\Delta_{\mathrm{yi}}$ & $\mathrm{V}_{\mathrm{i}} / \mathrm{V}_{\mathrm{E}}$ & $\mathrm{k}_{\mathrm{i}}$ & $\mathrm{M}_{\mathrm{i}}$ & $\mathrm{V}_{\mathrm{i}} / \mathrm{V}_{\mathrm{E}}$ & $\mathrm{k}_{\mathrm{i}}$ & $\mathrm{M}_{\mathrm{i}}$ \\
\hline 1 & 1.00 & 1.000 & 0.472 & 0.472 & 0.236 & 0.283 & 0.283 & 0.141 \\
\hline 2 & 1.25 & 1.563 & 0.242 & 0.155 & 0.151 & 0.226 & 0.145 & 0.141 \\
\hline 3 & 1.50 & 2.250 & 0.140 & 0.062 & 0.105 & 0.189 & 0.084 & 0.141 \\
\hline 4 & 1.75 & 3.063 & 0.088 & 0.029 & 0.077 & 0.161 & 0.053 & 0.141 \\
\hline 5 & 2.00 & 4.000 & 0.058 & 0.015 & 0.058 & 0.141 & 0.035 & 0.141 \\
\hline$\sum$ & - & - & 1.000 & 0.733 & - & 1.000 & 0.600 & - \\
\hline
\end{tabular}


Table 3: Data for the example structure in Figure 8

\begin{tabular}{|c|c|c||c|c||c|c|}
\hline \multicolumn{3}{|c||}{ Properties } & \multicolumn{2}{c||}{ Conventional } & \multicolumn{2}{c|}{ Arbitrary } \\
\hline 1 & 2 & 3 & 4 & 5 & 6 & $\mathrm{~V}_{\mathrm{i} \text { i. }}$ \\
\hline No. & $\mathrm{h}_{\mathrm{c}}$ & $\Delta_{\mathrm{y}}$ & $\mathrm{V}_{\mathrm{ic}}$ & $\mathrm{k}_{\mathrm{ic}}$ & 0.082 & 0.082 \\
\hline 1 & 1.00 & 1.000 & 0.047 & 0.047 & 0.326 & 0.652 \\
\hline 2 & 2.00 & 0.500 & 0.374 & 0.748 & 0.184 & 0.276 \\
\hline 3 & 1.50 & 0.667 & 0.158 & 0.237 & 1.000 & 1.748 \\
\hline$\Sigma$ & - & - & 1.000 & 1.827 & & \\
\hline
\end{tabular}

\subsection{A Structure Supported by Columns with Unequal Depths}

This example element is similar to that seen in Fig. 6. However, in this symmetrical variant, shown in Fig. 8, the columns are of equal heights but have different depth, $h_{\mathrm{c} i}$. The conventional allocation of seismic shear forces would follow the principles described in connection with the model element shown in Fig. 5(a)

Component shear forces and corresponding stiffness are recorded in columns 4 and 5 of Table 3. An alternative arbitrary choice for column strength may be made, whereby shear forces are made proportional to $h^{2}{ }_{\text {ci }}$, rather than $h^{3}{ }^{3}$. Thereby it will be found that the ratio of the reinforcement in these columns will be very nearly the same. This suggests a better balance of strength. The column shear forces and stiffness so arrived at are presented in columns 6 and 7 of Table 3. The corresponding bilinear simulation of column shear force-displacement responses are depicted in Fig. 9, where the restrictions on displacement ductilities are also shown. A comparison of the overall response of the two different elements shows negligible differences. Conventional strength allocation, shown by the dashed lines, would result in $4.5 \%$ increase in element stiffness.

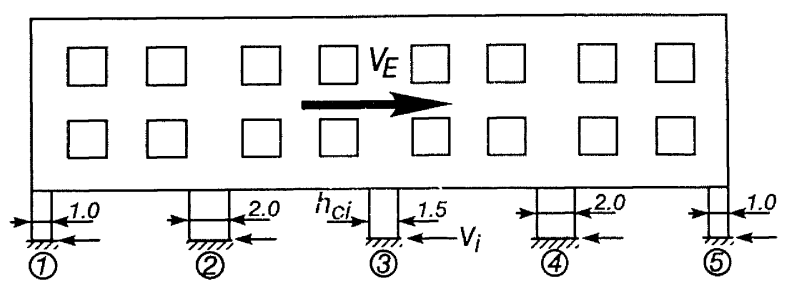

Figure 9: Force-displacement modeling of the structure shown in Fig. 8.

\section{A CLASSIFICATION OF TORSIONAL SYSTEMS}

\subsection{Degree of Restraint}

It has been suggested [17] that, as part of routine structural design, when unidirectional seismic attacks in the principal directions of the building are considered separately, two types of torsional systems should be distinguished. Special features of the behaviour of each of these are reviewed subsequently.

As stated in Section 4.1, when considering the torsional response of buildings, three familiar locations in plan need to be identified [2]. The centre of the distributed mass over the plan area of the building is identified as CM. The centre of element stiffness or centre of rigidity, or shear centre of the system is abbreviated as CR. The position of the resultant of the nominal strengths of elements, $V_{n i}$, is the centre of strength, $\mathrm{CV}$, of the system.

\subsubsection{Torsionally unrestrained (TU) systems}

Figure 8: A structure supported on columns with different depths.

(a) Static actions. In the absence of at least two noncollinear elements, transverse to the direction of the base shear, no torque associated with static lateral force $V_{E y}$. can be resisted by a ductile system. Therefore, when, due to the 
base shear, the translatory elements have entered the inelastic domain, no restraint to twist of the system will be available. Figures 11(a) to 13(a), 14, 15(a) and 16(a) show typical examples. It also implies that, when only static lateral forces are considered, no eccentricity of the total strength, $V_{E y}$, that could be possibly utilized, can exist.

(b) Dynamic actions. When dynamic actions are considered, the rotary inertia of the distributed mass can introduce a torque, as discussed subsequently in greater detail, but only if at least one of the translatory elements has sufficient reserve strength. Therefore, in such cases the total strength, $V_{E y}$, developed in the ductile translatory elements, may be eccentric. Figures 13(a), 14 and 16(a) show typical cases.

In the model shown in Fig. 10, the rotary inertia of the distributed mass may generate a torque which is larger than that associated with $\mathrm{e}_{\mathrm{vx}}$. The system twist due to this eccentricity of the total strength, $V_{E y}$, of the two translatory elements, may mobilize an additional torque, utilizing a force couple operating with a lever arm of $\mathrm{e}_{\mathrm{vy}}$. Thus in this system, the base shear $V_{E y}$ may generate a base shear also in the $x$ direction, $V_{E x}$. However, in terms of static forces this system too is torsionally unrestrained.

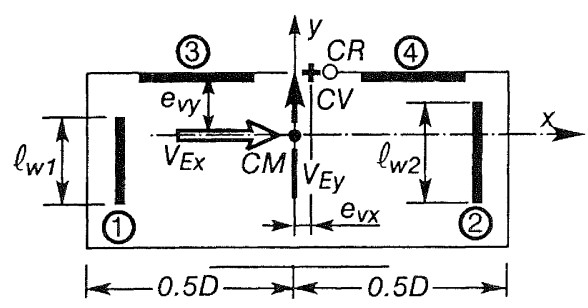

Figure 10: ATU system with one eccentric transverse element.

\subsubsection{Torsionally restrained (TR) systems}

When transverse elements in at least two planes are provided, a torque, for example due to strength eccentricity, can be resisted after all translatory elements have yielded. Thereby rotational deformations of the diaphragm, i.e., twist, are restrained. This is particularly the case when the transverse elements remain elastic while they resist the torque generated. Designers are aware that such systems are preferable. Figures 13(c), 17 and 18 show typical example models.

\subsection{Types of Eccentricities}

All codes [6, 12] and most researchers [18, 19], conducting parametric studies, consider stiffness eccentricities, $e_{r}$, only. This is understandable because traditional approaches to torsional phenomena were primarily based on elastic response. However, it is postulated that strength eccentricities, $e_{v}$, are equally, if not more, important and that they give a better indication of behavioural features of ductile systems. Moreover, for reasons presented in Section 4.6, the designer has full control over strength eccentricity. Because stiffness is strength-dependent (Eqn.(1)), stiffness eccentricity is clearly related to strength eccentricity. If the former is reduced or eliminated, generally the latter will be small enough to have only a small effect, if any, on inelastic torsional displacements. Interrelationships between the two types of eccentricities are reviewed in Section 7.10.

For a better understanding of torsional phenomena both types of interdependent eccentricities, i.e., strength eccentricity, $e_{\mathrm{vx}}$, and stiffness eccentricity, $\mathrm{e}_{\mathrm{rx}}$, should be considered. Accordingly the following four categories of eccentricity combinations with respect to a base shear in the $\mathrm{y}$ direction, to be subject in Section 7 to detailed examinations, will be reviewed

$\begin{array}{lll}\text { (i) } & \mathrm{e}_{\mathrm{vx}}=0 \text { and } & \mathrm{e}_{\mathrm{rx}}=0 \\ \text { (ii) } & \mathrm{e}_{\mathrm{vx}} \neq 0 \text { and } & \mathrm{e}_{\mathrm{rx}} \neq 0 \\ \text { (iii) } & \mathrm{e}_{\mathrm{vx}}=0 \text { but } & \mathrm{e}_{\mathrm{rx}} \neq 0 \\ \text { (iv) } & \mathrm{e}_{\mathrm{vx}} \neq 0 \text { but } & \mathrm{e}_{\mathrm{rx}}=0\end{array}$

These eccentricities are evaluated with respect to the base shear, $V_{E y}$, at the centre of mass, CM. Mass eccentricities, $e_{m x}$, with respect to the geometric centre of the plan may also exist. These, however, will affect only the rotary inertia of the distributed mass, which may be taken into account in the evaluation of dynamic response (Section 7.2).

\subsection{Directional Effects}

In conformance with typical code [6] requirements, only unidirectional seismic attacks, independently in the two principal orthogonal directions of a building, are considered by designers.

An earthquake-generated instantaneous base shear may, however, act in any direction. Researchers prefer to use the term "bi-directional effects". A study of this involves usually the simultaneous orthogonal dynamic response of ductile systems to a selected suit of earthquake records. This technique cannot be considered presently as a viable tool in routine design. The term preferred here [20] is "skew seismic attack". It is postulated that an in-depth study of unidirectional ductile response, independently in the principal orthogonal directions, can usually provide sufficient information with respect to torsional mechanisms and consequent displacement demands under a skew attack Relevant details [20] are not considered in this paper.

\section{BASE SHEAR- TORQUE AND DISPLACEMENT RELATIONSHIPS}

The examination of the interaction between the base shear and the maximum torque that can be sustained simultaneously, was introduced in an enlightening study [21]. These relationships, to be illustrated in this section with a number of examples, are intended to assist in the understanding of structural behaviour. The relationships are used here also to illuminate certain differences between static and dynamic equilibrium criteria. This aspect is of some importance to the majority of designers, who, like the author, have been using code-stipulated equivalent static forces, and associated mechanisms, when providing seismic resistance in buildings. It is emphasized that the relationships, while strongly promoting understanding of fundamental issues of 
torsional phenomena, are not pertinent to design applications.

Instead of presenting the relationships in abstract terms, specific examples for distinct classes of systems have been chosen to introduce the relevant principles. The examples consider side by side torsionally unrestrained, TU, and restrained, TR, systems, as defined in section 6.1. Base shear-torque relationships, subsequently abbreviated as BST, compare only potential strengths with disregard of its origin and ensuing deformations. However, where instructive, comments will be offered with respect to elastic or inelastic displacements of elements and the origin of actions.

The boundary of a BST surface, such as shown in Figs. 11 to 13, represents the limits of element strength development. Any point within the boundary signifies elastic behaviour and is thus of no interest in terms of design for ductile response.

\subsection{A Symmetric System $\left(e_{\mathrm{vx}}=\mathrm{e}_{\mathrm{rx}}=\mathrm{e}_{\mathrm{mx}}=0\right)$}

First a symmetric example system, shown in Fig. 11 . subjected to a unidirectional unit base shear, $V_{E y}=1.00$, is considered. Elements (1), (2) and (T) have identical dimensions and nominal strengths, $\mathrm{V}_{\mathrm{ni}}=0.50$, and hence identical stiffness. Element (3) of the TU system is not affected by the base shear under consideration. It has been provided to cater for seismic resistance in the $\mathrm{x}$ direction. It is evident that at the commencement of yielding of the translatory elements (1) and (2), no torque can be sustained by this TU system, as the inelastic translatory elements cannot absorb any additional force. Under the action of a torque, without any base shear, the torsion-induced force in the elements will be $M_{l} / A= \pm 0.5$. This force is plotted along the vertical axis of the BST surface, shown in Fig. 11(b). The linear relationship between the four points show that, any torque which may be applied to the system will reduce its base shear capacity. Therefore, this restriction applies only to elastic response. In terms of ductile response, relying on the simultaneous development of the nominal strength of both elements, the BST surface is of no interest to the designer.

As Fig. 11(c) shows, the (T) type transverse elements enable a torque, additional to that applicable to the example system in Fig. $11(\mathrm{a})$, of $\mathrm{M}_{1}=0.5 \mathrm{~B} \approx 0.38 \mathrm{~A}$, to be sustained. Any torque smaller than this could be sustained while the inelastic elements (1) and (2) approach the ultimate limit state. Therefore, the transverse elements will. restrain the twist due to a torque that may be generated by an unpredictable small eccentricity or other causes.

Interaction relationships for $\mathrm{TU}$ systems, associated with $\mathrm{V}_{\mathrm{Ey}}$ are shown in this and subsequent the figures by full lines and those for TR systems by dashed lines.

\subsection{A Mass-eccentric System ( $\left.e_{v x}=e_{r x}=0, e_{x m} \neq 0\right)$}

Figure 12 illustrates the same structural system where a mass eccentricity of $e_{m x}=0.15 \mathrm{~A}$ exists. As suggested by statistics, the nominal strengths of the two translatory elements (1) and (2), corresponding to the unit base shear, have been made 0.65 and 0.35 respectively. Because, as in the previous example, all elements have the same dimensions, in accordance with Eqn.(1) stiffness are proportional to these nominal strengths. Therefore, $\mathrm{CM}, \mathrm{CR}$ and $\mathrm{CV}$ coincide and there are no stiffness and strength eccentricities. Contrary to traditional notions, implied in current seismic codes, this idealized system will not be subject to any twist.

The BST surface, shown in Fig. 12(b) indicates that, as in the previous case, no torque can be sustained when the unit base shear is sustained. It is only of academic interest that, when the base shear is reduced to $0.3 \mathrm{~V}_{\mathrm{Ey}}$, the maximum torque of $0.455 \mathrm{~A}$ could be sustained by the TU systems. The response of the structure with such a small base shear strength is of no interest to the designer. When transverse elements, as in Fig. 12(c), are provided, a significant torque can be developed simultaneously with the unit base shear. If strength provided are as intended, in spite on mass eccentricity, the system shown in Fig. 12, should not be affected by twist. Therefore, elements (1) and (2) with identical dimensions should be subjected to identical displacement ductility demands.

\subsection{A System with Identical Strength and Stiffness Eccentricities $\left(e_{v x}=e_{r x} \neq 0, e_{n x}=0\right)$}

While the designer should intend to assign equal strengths to the two potentially ductile elements, as in Fig. 11(a), this is most unlikely to be achieved in structures, as constructed. Fig. 13(a) shows a hypothetical and extreme case, when the nominal strength of element (1) turned out to be $50 \%$ in excess of that intended. Thereby, as shown in Fig. 13(a), a strength eccentricity of $e_{v x}=-0.1 \mathrm{~A}$ will result. As a consequence the base shear capacity of the system increased to $1.25 \mathrm{~V}_{\mathrm{Ey}}$. Element dimensions, and hence yield displacements have not been changed. With the increase of the strength of element (1), its stiffness will also increase by $50 \%$. Hence stiffness and strength eccentricities will again be identical. Note that there should be no intentional strength eccentricity in 2-element systems because a logical strength assignment would follow from statics. Researchers routinely investigate 2-element eccentric torsionally unrestrained systems.

The BST surface applicable to this TU system, shown by full lines in Fig. 13(b), when compared with those plotted for the previous two cases, demonstrates two distinct features.

(i) The full enhanced strength of the system can only be achieved if an externally applied torque of $\mathrm{M}_{1}=0.1 \times 1.25$ $= \pm 0.125 \mathrm{~A}$ is introduced.

(ii) In the absence of this torque, as the dashed border lines of the shaded areas show, only a unit base shear can be generated. This implies that in compliance with static equilibrium, element (1), with a strength of 0.75 , cannot yield.

The enhancement of the torsional capacity by transverse elements ( $T$ ) is similar to those seen previously. Therefore, Figs. 13(b) and (c) need no further explanation.

\subsection{An Asymmetric TU System with Strength and Stiffness Eccentricities $\left(\mathrm{e}_{\mathrm{vx}} \neq 0, \mathrm{e}_{\mathrm{rx}} \neq 0, \mathrm{e}_{\mathrm{mx}}=0\right)$}

Because of some interesting features of behaviour, the next example is presented in greater detail in Fig. 14. It is similar 
to that considered in Fig. 13, with the exceptions that, the geometry of the elements (1) and (2) is different. Once again, it is assumed that in terms of $V_{E y}$ the strength element (1) turned out to be $50 \%$ larger $(0.75)$ than intended, while that of element (2) is 0.5 . The resulting strength eccentricity is again $\mathrm{e}_{\mathrm{vx}}=-0.1 \mathrm{~A}$. Because of the different lengths of the elements, and hence different relative yield displacements, i.e., $\Delta_{\mathrm{y}} \propto 1 / \ell_{\text {wi }}$, the relative stiffness are $\mathrm{k}_{1}=0.75 / 1.0=0.75$ and $\mathrm{k}_{2}=0.50 / 1.4=0.357$, respectively. This results in a stiffness eccentricity of $e_{\mathrm{rx}}=-0.178 \mathrm{~A}$, as shown in Fig. 14(a). Because a BST surface correlates strengths only, the one relevant to this TU system is the same as that shown by full lines in Fig. 13(b).
To be able to better appreciate the seismic behaviour of this model, equilibrium criteria and associated element deformations need be studied. To this end Fig. 14(b) shows the forces satisfying static equilibrium. As Fig. 13(b) shows, in the absence of a static torque, the total base shear capacity is restricted to unity. At this stage element (2) would commence yielding while the relative displacement of element (1) is limited to $0.5 / 0.75=0.67<\Delta_{\mathrm{y} 1}=1.0$. If element (2) is permitted to be displaced to its maximum capacity of $7.0\left(\mu_{\Delta 2}=5.0\right)$, the diaphragm profile shown by the dashed sloping line in Fig. 14(c) would result. This would restrict the displacement at CM to only 3.83 units.

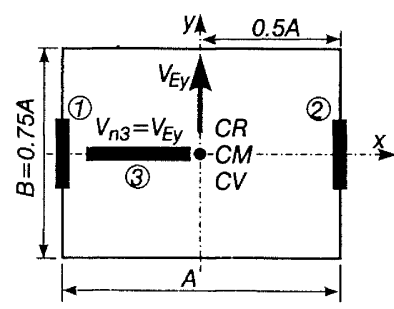

(a) TU System

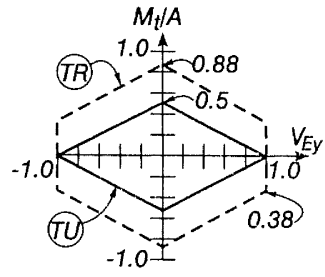

(b) BST Surface

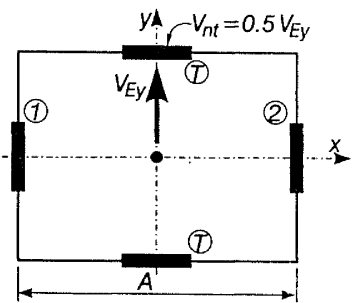

(c) TR System

Figure 11: A TU and TR symmetric-plan structure.

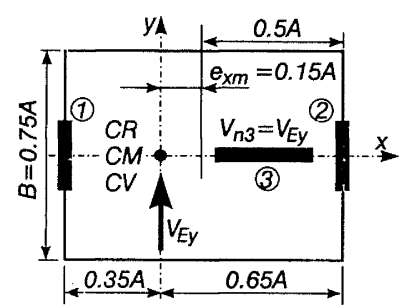

(a) TU System

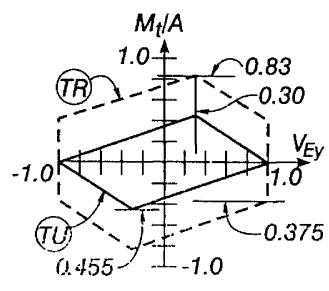

(b) BST Surface

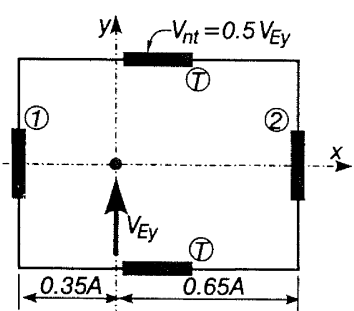

(c) TR System

Figure 12: ATU and TR structure with mass eccentricity only.

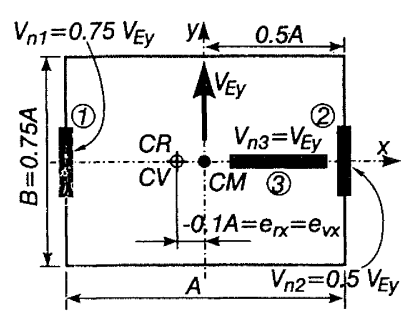

(a) TU System

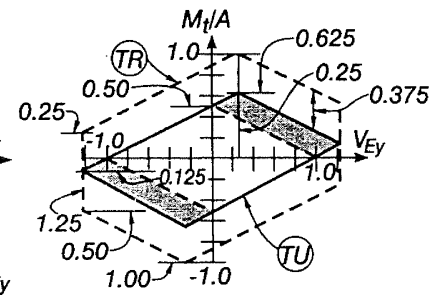

(b) BST Surface

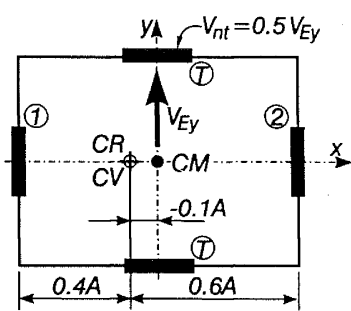

(c) TR System

Figure 13: ATU and TR structure with identical stiffness and strength eccentricities.

The reserve strength of 0.25 of element (1) could only be mobilized if an equal opposite force could be introduced at CM. As Fig. 14(d) shows, this would require the application of an external torque of $\mathrm{M}_{\mathrm{td}}=0.125 \mathrm{~A}$. Because of the anticlockwise rotation encountered (Fig. 14(c)), the rotary inertia of the distributed mass will be mobilized with its tendency to oppose this twist. Thus the dynamically introduced actions, shown in Fig. 14(d), will lead to a clockwise rotation of the diaphragm, as depicted in Fig 14(e).

The superposition of these two scenarios, shown in Fig. 14(f), results in the final state of dynamic equilibrium and possible displacement patterns shown in Fig. 14(g). zThe full line profile in Fig. $14(\mathrm{~g})$ shows the optimal condition when both elements develop their full displacement ductility capacity of 5 . The more likely profile is that shown by the 
dashed line in the same figure. Criteria influencing the angle of twist in this type of TU system is further discussed in Section 7.10

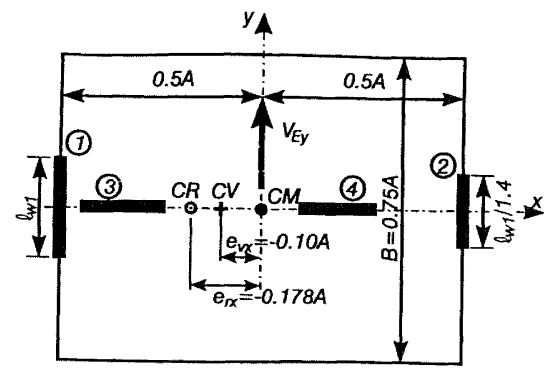

(a) Plan
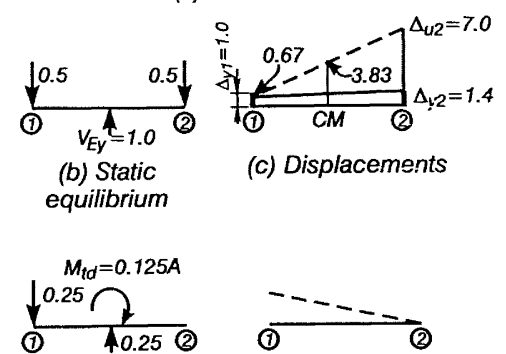

(d) Dynamic equilibrium

(e) System twist
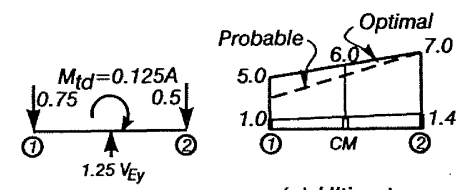

(f) Total equilibrium

(g) Ultimate displacement

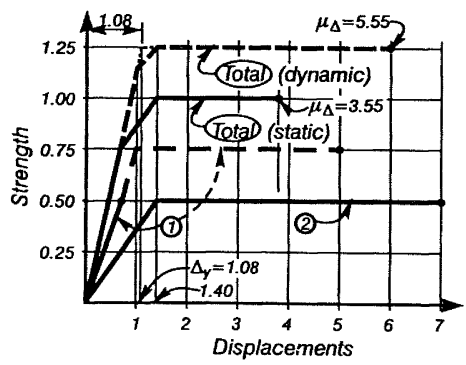

(h) Force-displacement modelling
Figure 14(h) presents the force-displacement relationships for both elements and the system corresponding with criteria of static (full lines) and dynamic (dashed lines) equilibrium. This example attempted to explain, how during dynamic response the rotary inertia of the mass enables more favourable element displacements and hence increased system displacement capacities to be developed. This is the reason why torsional mechanisms based on static equilibrium criteria [4, 5] lead to overly conservative (Fig. 14(c)) prediction of ultimate displacement and hence displacement ductility demands [20]. Ductilities shown in Fig. 14(h) have been described as in Fig. 5. While analytical studies confirm this trend, the quantification in a simple way, suitable for routine design, of this phenomenon has so far eluded research efforts. However, it is pursued.

The actions developed as a result of dynamic mass rotation of the TU system are shown by the shaded area in Fig. 13(b). BST surfaces do not consider effects of stiffness eccentricity. However, as Section 7.10 will explain, for a system with given geometry, stiffness and strength eccentricity are uniquely related to each other.

7.5 An Asymmetric TU System with Stiffness Eccentricity only $\left(e_{\mathrm{vx}}=0, \mathrm{e}_{\mathrm{rx}} \neq 0, \mathrm{e}_{\mathrm{nxx}}=0\right)$

The same structure as shown in Fig. 14(a) is considered except that, corresponding with a common sense choice, the same strength $(0.50)$ has been assigned to each of the two elements. Therefore, in this TU system, shown in Fig. 15(a), the relative stiffness of the elements will be $\mathrm{k}_{1}=0.5 / 1.0=$ 0.50 and $k_{2}=0.5 / 1.4=0.357$, respectively, resulting in a stiffness eccentricity of $e_{r x}=-0.083 \mathrm{~A}$. The strength-dependent BST surface, shown in Fig. 15(b) will be the same as that in Fig. 11(b).

Under static forces the simultaneous attainment of the yield displacements of the two elements, should occur. However, during this elastic response some anti-clockwise rotation of the diaphragm will occur, immediately mobilizing during dynamic response the rotary inertia of the mass. The small torque so generated will tend to reduce the twist and hence will cause element (1) to commence yielding just before element (2). The corresponding force-displacement relations for the elements and the system are presented in Fig. 15(c).

Figure 14: An asymmetric TU system with stiffness and strength eccentricities.

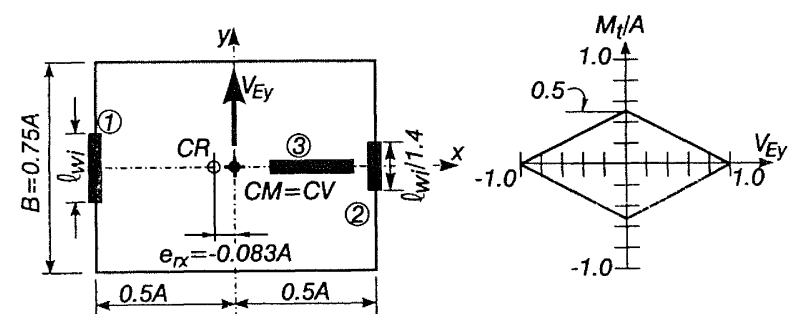

(a) A TU System (b) BST Surface

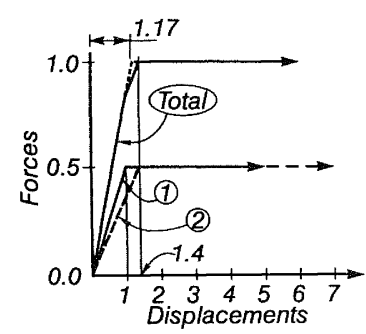

(c) Force-displacement relationships

Figure 15: A TU system with only stiffness eccentricity. 


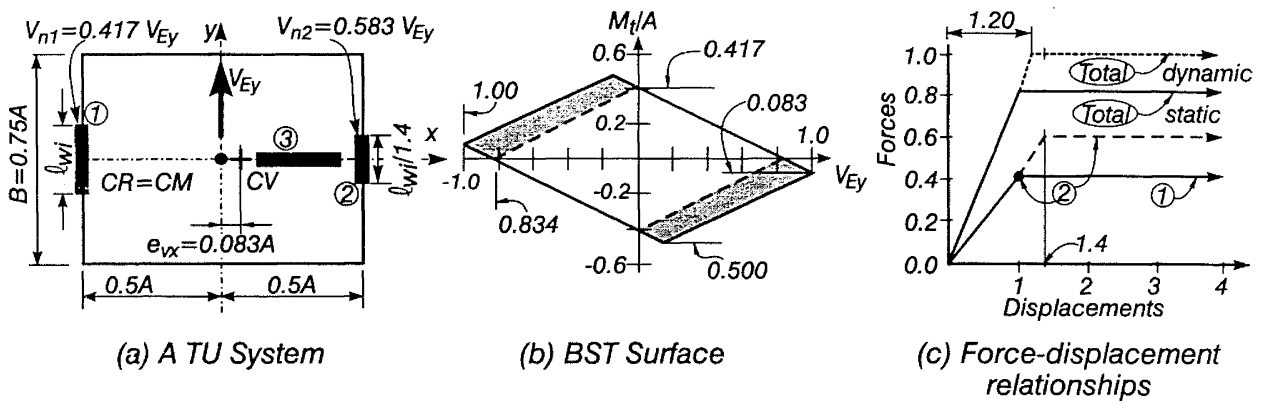

Figure 16: A TU asymmetric system with strength eccentricity only.

7.6 An Asymmetric TU System with Strength Eccentricity only $\left(e_{\mathrm{vx}} \neq 0, \mathrm{e}_{\mathrm{rx}}=0, \mathrm{e}_{\mathrm{nx}}=0\right)$

The above example model may be modified in order to illustrate in Fig. 16 conditions which arise when stiffness eccentricity is eliminated but a strength eccentricity remains. As stated earlier the two types of eccentricities may coincide only if all translatory elements have the same yield displacement. A strength eccentricity of $e_{v x}=0.083 \mathrm{~A}$ resulted from the choice of element strengths of 0.417 and 0.583 , respectively, leading to identical element stiffness of $\mathrm{k}_{1}=0.417 / 1=\mathrm{k}_{2}=0.583 / 1.4=0.417$. Because of the absence of stiffness eccentricity, this system is often mistakenly referred to as "torsionally balanced" [22].

Under static actions the maximum base shear is twice the strength the weaker of the elements, i.e., $2 \mathrm{~V}_{\mathrm{nl}}=2 \times 0.417=$ 0.834 units. This condition is represented by the dashed line smaller diamond shaped BST surface in Fig. 16(b). At this level of base shear, element (1) will commence yielding, resulting in a clockwise rotation of the diaphragm. This then may trigger the rotating mass to introduce a "dynamic torque" with a maximum intensity of $\mathrm{M}_{1}=-0.083 \mathrm{~A}$. This then will lead to the ductile response of both elements. The corresponding BST surface is shown by the full outline in Fig. 16(b). As in Fig. 13(b), the shaded area in Fig. 16(b) shows the additional actions that could be generated only during dynamic response. The linearized force-displacement response of the elements and the system for both the static and dynamic scenarios are presented in Fig. 16(c).

\subsection{Torsionally Unrestrained Multi-element Systems}

The principles reviewed in the previous subsections apply equally to the more common systems in which, as Fig. 17(a) shows, more than two elements resist the base shear in one direction. When transverse lateral force-resisting elements are placed in one plane only, collinear with $\mathrm{CM}$, no torsional restraint exists. To study some relevant features which designers may utilize to improve seismic behaviour, once again a specific example will be considered.

An idealized, but perhaps extreme, arrangement of lateral force-resisting elements, comprising rectangular cantilever walls of identical thickness and heights, are shown in Fig. 17(a). The lengths of the equidistant elements (1) to (4) shown, are such that their relative second moment of area, being proportional to $l_{i}{ }^{3}$, bear the ratios $1: 2: 4: 8$ to each other. This was also shown in Fig. 4. The resulting stiffness eccentricity, based on the conventional definition of element stiffness, is $\mathrm{e}_{\mathrm{rx}}=0.189 \mathrm{~A}$. If strength were to be assigned similarly (See Fig. 5(a) and Table 1), CV and CR, as shown in Fig. 17(a), would coincide. Normalized forces so derived are listed in column 3 of Table 4 . However, a routine torsional analysis, based on the torsional stiffness, provided by the 4 elements, would be carried out, to eliminate strength eccentricity. Column 4 of Table 4 shows the corresponding share of the unit base shear, so derived for each element. Code-specified manipulations of the original stiffness eccentricity $(0.189 \mathrm{~A})$, not considered in this study, would result in slight modifications of element strengths, accompanied by some increase of the base shear requirements and moderate strength eccentricity. If element stiffness were based on Eqn. (1) and on strengths resulting in $\mathrm{e}_{\mathrm{rx}}=\mathrm{e}_{\mathrm{vx}}=0.189 \mathrm{~A}$, as in column 4 of Table 1 , the true stiffness eccentricity would turn out to be $e_{\mathrm{rx}}=0.247 \mathrm{~A}$.

While the traditional allocation to elements of strength is satisfactory because equilibrium criteria are met, it should be noted that in the customary process [6] of deriving element strength widely used in relevant publications $[18,19,23]$, stiffness were assumed to be unchanged. Realistic strengthbased stiffness, as defined by Eqn.(1), would result in a stiffness eccentricity significantly less then that based on traditional design practice.

If the strength allocation given in column 4 of Table 4 is adopted, the relative stiffness, $\mathrm{k}_{\mathrm{ir}}$, of each element, as shown in column 5 , is readily established. These realistic stiffness, $\mathrm{k}_{\mathrm{ri}}$, lead to a stiffness eccentricity of $\mathrm{e}_{\mathrm{rx}}=0.085 \mathrm{~A}$, that is $45 \%$ of that derived using the traditional technique. The latter ignores the fact that a change of element strength results in a proportional change of its stiffness.

As stated previously, within reasonable limits, strength to elements can be assigned arbitrarily. Such a choice was made when adopting values of $\mathrm{V}^{*}{ }_{n i}$ given in column 6 of Table 4 , also resulting in $e_{v x}=0$. The correspondingly re-defined stiffness, $\mathrm{k}_{\mathrm{r}}{ }_{\mathrm{r}}$, resulting in $\mathrm{e}_{\mathrm{rx}}=0.074 \mathrm{~A}$, are recorded in column 7 of Table 4 . The associated positions of $\mathrm{CV}^{\prime}$ and $\mathrm{CR}^{\prime}$ are shown in Fig. 17(a). 
Table 4: A comparison of element strengths and stiffness relevant to the structure shown in Fig.17(a)

\begin{tabular}{|c|c|c|c|c||c|c||c|}
\hline 1 & 2 & 3 & 4 & 5 & 6 & 7 & 8 \\
\hline No & $1_{\mathrm{wi}}$ & $\mathrm{V}_{\mathrm{i}} \propto \mathrm{k}_{\mathrm{ic}}$ & $\mathrm{V}_{\mathrm{ni}}$ & $\mathrm{k}_{\mathrm{ir}}$ & $\mathrm{V}^{{ }_{\mathrm{ni}}}$ & $\mathrm{k}{ }_{\mathrm{ir}}$ & $\Delta_{\mathrm{yi}}$ \\
\hline 1 & 1.00 & 0.067 & 0.166 & 0.166 & 0.133 & 0.133 & 1.000 \\
\hline 2 & 1.26 & 0.133 & 0.244 & 0.307 & 0.266 & 0.335 & 0.794 \\
\hline 3 & 1.59 & 0.267 & 0.314 & 0.499 & 0.365 & 0.580 & 0.629 \\
\hline 4 & 2.00 & 0.533 & 0.276 & 0.552 & 0.236 & 0.472 & 0.500 \\
\hline$\Sigma$ & & 1.000 & 1.000 & 1.525 & 1.000 & 1.000 & \\
\hline \multicolumn{2}{|c|}{ Eccentricity } & $0.189 \mathrm{~A}$ & 0.000 & $0.085 \mathrm{~A}$ & 0.000 & $0.074 \mathrm{~A}$ \\
\hline
\end{tabular}

Notes:

Column 1: Element number, i

Column 2: Relative length of elements, $1_{\text {wi }}$

Column 3: Relative element strength when made proportional to stiffness $\mathrm{k}_{\mathrm{ic}} \propto \mathrm{l}_{\text {wic }}^{3}$

Column 4: Element relative nominal strengths required after the traditional allowance for torsional demands on the elastic system has been employed resulting in $\mathrm{e}_{\mathrm{vx}}=0$

Column 5: Redefined strength-dependent relative stiffness of elements based on Eqn.(1)

Column 6: An arbitrary distribution of relative element strengths also resulting in zero strength eccentricity

Column 7: Relative element stiffness based on strengths given in column 6

Column 8: Element yield displacements, normalized in terms of that of element (1), as column 2 of Table 1.

Figure 17(b) presents displacement profiles of the diaphragm, used here to illustrate the sensitivity of this system to torsional phenomena and opportunities for early design judgements. Column 8 of Table 4 lists the relative yield displacements of the elements. From Eqn.(8) the relative reference yield displacement of the system with strength allocations as given in column 6 , plotted to scale in Fig. 17 (b), is $\Delta_{\mathrm{y}}=\sum \mathrm{V}^{*}{ }_{\mathrm{n} i} / \sum \mathrm{k}_{\mathrm{ri}}=1 / 1.52=0.66$. It is seen that if the displacement ductility of elements is not to exceed 5.0, the uniform translatory displacement of the system must be restricted to $5 \times 0.5=2.5$ displacement units. This case corresponds to the system displacement ductility having to be limited to $2.5 / 0.66=3.8$. This will correspond very nearly to the case when $e_{v x}=0$. However, on account of a small stiffness eccentricity $\left(e_{\mathrm{rx}}=0.074 \mathrm{~A}\right)$ a small clockwise twist is to be expected.

Table 4 listed the desired nominal strengths of elements, $\mathrm{V}{ }^{*}{ }_{\text {ini }}$, which resulted from the decision to make $\mathrm{e}_{\mathrm{vx}}=0$. This will not be possible to be achieved in the structure as constructed. If one or both elements to the right of $\mathrm{CM}$ will have excess strength, eccentricities will be larger than intended. Therefore, some additional positive twist must be expected. However, the maximum twist that could be attained without exceeding the stipulated element displacement limits, is $\theta_{\mathrm{t}, \mathrm{max}}=5\left(\Delta_{\mathrm{y} 3}-\Delta_{\mathrm{y} 4}\right) /(\mathrm{A} / 3) \approx 1.94 / \mathrm{A}$.

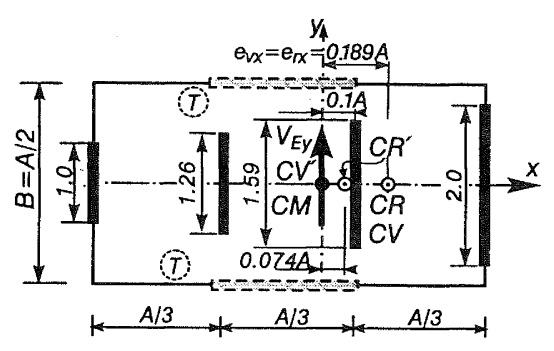

(a) Plan

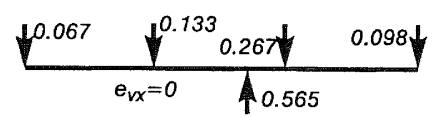

(c) Static forces in equilibrium

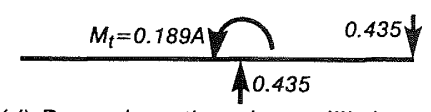

(d) Dynamic actions in equilibrium

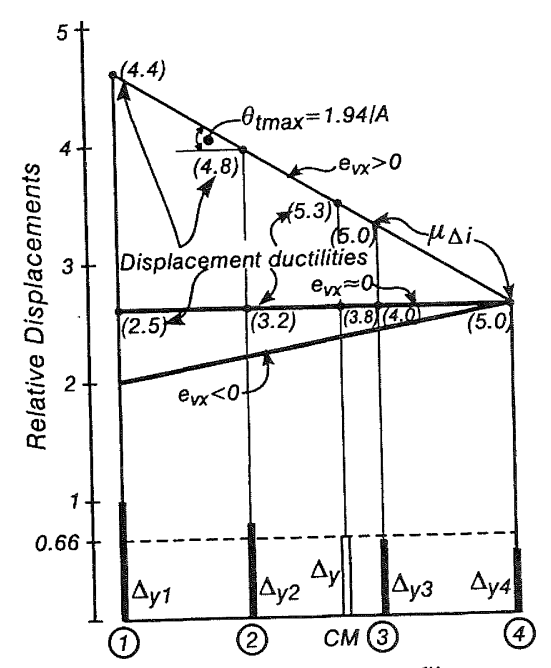

(b) Displacement profiles

Figure 17: A torsionally unrestrained multi-element system. 
The corresponding displacement profile is shown at the top of Fig. 17(b). It is seen that the corresponding displacement ductilities, shown by the bracketed quantities, are all of the order of 5 , indicating the most efficient utilization of the ultimate element displacement capacities. This very large twist is not likely to arise in the structure. It indicates, however, that, when $e_{\mathrm{vx}}>0$, this system is extremely tolerant with respect to torsional demands. To increase the displacement ductility capacity of the system to values larger than 3.8 , a deliberate introduction of a moderate positive strength eccentricity would be beneficial. This beneficial feature of torsional mechanisms escapes from the attention of the designer who meticulously follows existing code rules.

When any or both of the elements to the left of CM end up with excess strength, not a likely event in this example, a negative strength eccentricity will result. A typical displacement profile associated with this scenario, shown by the line marked $e_{v x}<0$ in Fig. 17(b), indicates that the displacement ductility demand on the system should be reduced to less than 3.8 , if the demand on element (4) is not to exceed its capacity. It is evident that it will be easy for the designer to avoid this undesirable scenario.

In considering admissible displacement profiles, the limitations imposed on the absolute displacement must also be considered (Section 2).

To illustrate once more the contribution to the understanding of torsional phenomena of equilibrium criteria, two details are added to Fig. 17. The distribution of element strengths, which resulted in an extreme strength eccentricity of $\mathrm{e}_{\mathrm{vx}}=$ $0.189 \mathrm{~A}$, recorded in column 3 of Table 4 , may be temporarily separated into two groups. Fig. 17(c) shows the nominal strengths of elements (1) to (3) with that of element (4) reduced, however, by more than $80 \%$. This combination results in no strength eccentricity but also a significantly reduced based shear capacity to $56.5 \%$. When the static base shear attains this value, al but element (4) would commence yielding. Thus a static mechanism could never develop the full nominal strength of this system. A clockwise twist would ensue. Figure 17(d) demonstrates how the remaining strength of element $(4), 0.533-0.089=0.435$, could be utilised. A torque of $M_{t}=-0.433 \times 0.435=-0.189 \mathrm{~A}$, generated by the rotary inertia of the mass, would enable the remaining strength of element (4), and hence the full base shear capacity of the system to be developed.

\subsection{Torsionally Restrained Multi-element Systems}

The relevance of the outlined principles are extended to cover structures more commonly encountered in practice. To this end the model shown in Fig. 17(a) is considered again, but with the (T) type transverse elements, with a nominal strength of $\mathrm{V}_{\mathrm{nt}}=0.5$, also present. Thus a torque up to $M_{1}=0.25 \mathrm{~A}$ could be sustained by the system. The static strength eccentricity of $0.189 \mathrm{~A}$ would utilise only $75 \%$ of the strength of the transverse elements. An additional dynamically induced torque of $0.061 \mathrm{~A}$ could be sustained before the transverse elements would commence yielding. At this stage control over twist would be lost and the system would degenerate into a partially torsionally unrestrained one.
Assuming that the properties of the transverse elements are the same as those of element (4), i.e., $\Delta_{\mathrm{yl}}=0.50$ units (Table 4) the twist associated with the onset of yielding of the (T) type elements would be $\phi_{\mathrm{l}}=2 \times 0.5 / \mathrm{B}=2 / \mathrm{A}$. This is similar to the optimal twist shown in Fig. 17(b) for the torsionally restrained system.

It is thus evident that when strength distribution is such that $\mathrm{e}_{\mathrm{vx}} \approx 0$, the system will be insensitive to displacement demands due to twist. However, because of the small angle of twist to be expected, as Fig. 17(b) shows, a significant reduction of the system displacement ductility capacity $\left(\mu_{\Delta} \approx\right.$ 3.8) must be expected.

Base shear-torque surfaces can be constructed for multielement models [10]. They can assist in the understanding of the differences between static strength and equilibrium criteria considered above.

Some researchers found no significant differences in the ductile response of torsionally unrestrained and restrained systems $[18,24]$. Others concur with the conclusions made here that the presence of transverse elements, capable of providing torsional resistance, beneficially affect the displacement demands on the principal translatory element. Presently it is difficult to make comparisons because the conclusions in most publications are based on the traditional definitions of strength-independent stiffness.

\subsection{Geometric Sensitivity to Element Displacement Demands}

The single most important parameter, which quantifies within a ductile system the displacement response of an element, is its yield displacement. The model structure in Fig. 17(a) and the distribution of the element yield displacements, seen in Fig. 17(b), clearly demonstrated that the system is not sensitive to moderate torsional demands associated with positive twist. Moreover, it shows how some twist can increase the displacement ductility capacity of the system.

Figure 18 presents two simplified and idealized 4-element systems. These intend to demonstrate the sources of torsional sensitivity. Figure 18(a) shows a geometrically symmetrical system with possible strength and hence stiffness eccentricity. Because strength eccentricities are not considered, traditional interpretations would fallaciously assume zero stiffness eccentricity. Element geometry in Plan I is such that the ratio of element yield displacements is $\Delta_{\mathrm{y} 1} / \Delta_{\mathrm{y} 2}=2$. Hence for uniform translation, displacements are controlled by the ductility capacity of elements (2). However, when, as a result of $\mathrm{e}_{\mathrm{vx}} \neq 0$, some twist occurs, large displacements of elements (1) are acceptable without exceeding their ductility capacity.

In the absence of type (3) transverse elements, the system may be shown to be torsionally very flexible. In most studies the use of such systems is discouraged [24]. With some eccentricity, not shown in Figure 18, large dynamically induced rotations could indeed occur. However, it should be noted that for the same ductility capacity, the limiting displacement for element (1) is twice that for element (2). Therefore, in a torsionally unrestrained system the extreme 
twist, shown by the dashed lines in Figure 18(b), could be acceptable. Of course drift limits need to be checked. Hence in terms of torsional response, the system (Figure 18(a)) is benign.

Plan II in Figure 18(c) shows a similar geometrically symmetrical system in which $\Delta_{y 1} / \Delta_{y 2}=1 / 2$. Irrespective of strength eccentricity, displacements are controlled by the ductility capacity of elements (1), having a rather small yield displacement. Any twist that may occur would have adverse effects. As a result of twist the displacement ductility capacity of the system would be reduced, if the displacement capacity of elements (1) is not to be exceeded.

\subsection{Sensitivity with Respect to Strength Eccentricity.}

To illustrate the relationship between eccentricities and the sensitivity to the torsional response of a torsionally unrestrained system, shown in Fig. 19, will be used. The model is similar to that shown in Fig. 14(a). Because element lengths and hence yield displacements are different, $\mathrm{CR}$ and $\mathrm{CV}$ will never coincide. A rational design approach would suggest that the unit base shear $V_{E y}$, be assigned to elements (1) and (2) in the proportions of 2 to 1 , respectively. Thus strength eccentricity is eliminated. With relative element stiffness of $\mathrm{k}_{1}=0.667 / \mathrm{l}=0.667$ and $\mathrm{k}_{2}=$ $0.333 / 1.4=0.238$, the corresponding stiffness eccentricity, details of which are not given here, will be $\mathrm{e}_{\mathrm{rx}}=-0.07 \mathrm{D}$.

A scenario is considered whereby, in terms of $V_{E y}=1.00$, the strength of element (1) is inevitably or intentionally increased by a factor $\lambda_{1}$, while that of element (2) remains unchanged at $1 / 3$. The corresponding eccentricities for the range of $1 \leq \lambda_{1} \leq 2$ are presented on the right side of Fig. 19. The relationships support the previously made claim that for a structure with given geometry the differences between the two eccentricities remain essentially constant. This underlines the fact that the two types of eccentricities cannot be randomly chosen, as it is commonly done in parametric studies. With the doubling of the intended strength of element (1), the total base shear capacity of the system will increase by $67 \%$.
Similar relationships, showing the effects of the increase of the strength of element (2), by the factor $\lambda_{2}$ are presented on the left side of Fig. 19. The doubling of the strength of this element results in this case only in $33 \%$ increase in the system strength.

The increase of system strength with increasing values of $\lambda_{1}$ or $\lambda_{2}$ are shown in Fig. 19 by straight dashed lines.
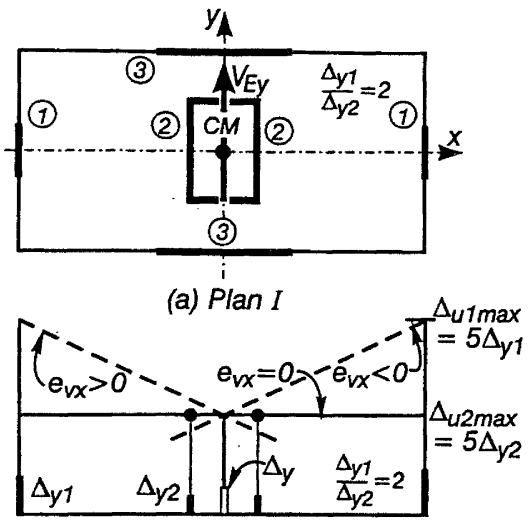

(b) Displacement pattern I

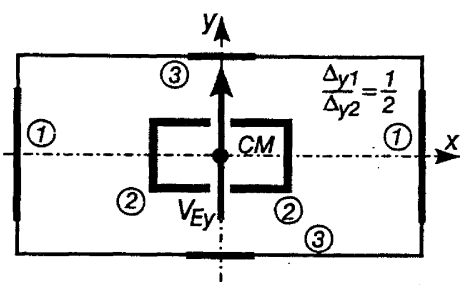

(c) Plan II

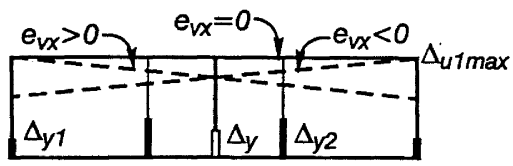

(d) Displacement pattern II

Figure 18: Element sensitivity to displacement demands.
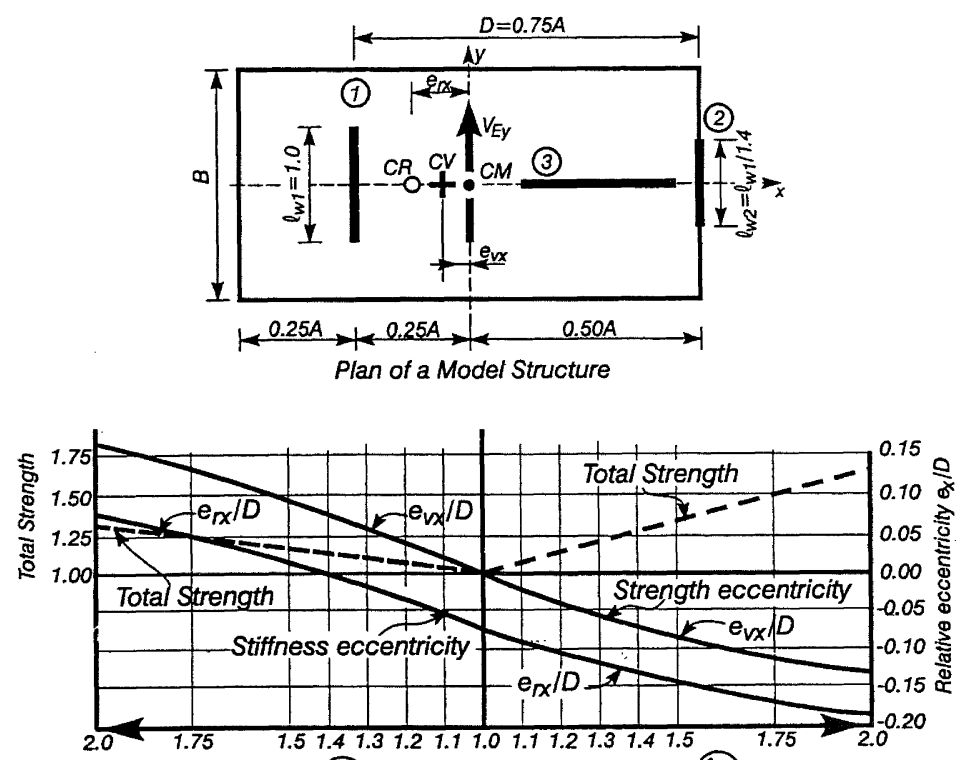

(2.)

(11)

Figure 19: Eccentricity relationships. 
The discussion in Section 7.3 and relevant to Fig. 13, attempted to illuminate the differences of system strength development under static and dynamic conditions. The excess strength of an element, $\left(\lambda_{\mathrm{i}}-1\right) \mathrm{V}_{\mathrm{i}}$, such as shown in Fig. 19 and 14(a), and the enhanced strength of the system, can be developed only by the dynamically induced rotary inertia of the mass. The larger the element excess strength and hence strength eccentricity, the smaller will be, for a given earthquake record, the dynamically induced twist, such as shown in Fig. 14(e). As a consequence the total twist, resulting in larger differences between critical element displacements, will increase (see Fig. 14(g)). The ductility capacity of the system will reduce if the ductility capacity of the element without excess strength is not to be exceeded. This adverse condition, resulting from increased eccentricities, will, however, be somewhat alleviated because the associated total strength enhancement of the system, shown by the dashed lines in Figs. 19, should result in a reduction of the displacement demand on the system.

\section{WHAT IS WRONG WITH THE SEISMIC CODE-DESIGN PROCEDURES FOR ASYMMETRIC STRUCTURES?}

(i) Relevant world-wide code provisions [6] are based on elastic structural behaviour. Yet the vast majority of buildings is designed for ductile seismic response.

(ii) While the ductile translatory behaviour of buildings and corresponding ductility demands are key issues of seismic codes, no corresponding reference is made to torsional phenomena.

(iii) Initial strength assignment to elements is made proportional to traditionally defined, i.e., geometrybased, element stiffness. The displacements of elements with such predetermined stiffness, are assumed to vary with the actual strength assigned to them. This is then fallaciously taken as the yield displacement of the element on which displacement ductilities are based.

(iv) It is widely recognised that a critical issue of the seismic design of ductile systems, is the estimation of element displacements associated with either performance or ultimate limit state criteria. Some codes impose limits on the twist of elastic systems. Corresponding inelastic deformations are, however, not addressed.

(v) Emphasis in codes is placed on providing torsional and enhanced translational strengths, with disregard of the ensuing effects on displacements.

(vi) No reference to the estimation of yield displacement of elements and that of the entire system is made in codes. Thereby the differences in displacement ductility demands on various elements, particularly those on critical edge elements, cannot be properly evaluated. (vii) The fact that stiffness is strength-dependent, is not recognised. Thereby, when element dimensions are set, stiffness eccentricities, based on traditional strength-independent definition of element stiffness, are fixed. Subsequent changes of element strengths, often radical, may significantly affect stiffness eccentricity. This remains unrecognised.

(viii) Computed stiffness eccentricities are manipulated. using additional nominated eccentricities, in order to arrive at increased strength demands on elements, considered to be adversely affected. Strength eccentricities, which are affected by such manipulations, are not considered.

(ix) Manipulations, based on hypothetical, yet not unrealistic, stiffness eccentricities, are used, instead of addressing directly the critical quantity, strength eccentricity, based on the nominal strength of elements, as constructed.

(x) The definitive relationship between stiffness and strength eccentricity is unrecognised. Hence the designer's attention is not drawn to the fact that strength eccentricity, and thereby stiffness eccentricity, can be readily controlled in any system with given geometry.

These comments should not be construed as a critique addressed to those researchers who, over several decades of dedicated work, developed techniques meeting the envisaged needs in seismic design. Some of the manipulations with eccentricities, extensively covered in the relevant literature, were intended, by means of parametric studies, to cater for inelastic displacement demands. Unfortunately these intentions are not transparent in current design provisions. Existing code recommendations grew out of the consideration of elastic behaviour only. As such they were widely endorsed by the design profession, including the author [23]. The comments, and indeed the major part of this paper, addresses issues which emerged from recently identified fallacies in seismic design [7], and corresponding promising adjustments in seismic design strategies $[9,10$, $11]$.

\section{CONCLUSIONS FOR DESIGN}

Based on the presentation of some concepts to aid a better understanding of torsional behaviour of ductile systems, issues with a likely appeal to structural designers are stated here.

(i) The primary aim in the seismic design of buildings should be to address displacements corresponding to stipulated performance criteria. Considerations relevant to the ultimate limit state are governed by displacement ductility capacities that can be provided for lateral force-resisting components and elements. Other, including serviceability, limit states necessitate the realistic evaluation of the absolute magnitudes of displacements.

(ii) A credible estimate of displacements, to satisfy the above criteria, can only be made if the estimation of the nominal yield displacement of the constituent components is realistic. Without a reasonable estimate 
of yield displacements, the proper stiffness of elements cannot be evaluated.

(iii) Because yield displacement is insensitive to the strength of an element, within the limits of common sense engineering judgement, strength to elements may be assigned in an arbitrary manner. This postulate, which implies that elements subjected to identical increasing displacements will, independently of their strength, commence yielding in a predetermined order, is in stark contrast with traditional design practice.

(iv) A major attraction of the above principle, is the freedom given to the designer to choose strengths that will serve a definite purpose. In terms of torsional phenomena, the aim is to locate the centre of strength, $\mathrm{CV}$, so that adverse affects of system twist are eliminated or at least minimized. There may be other motivations, such as achievement of more balanced strength demands on components with differing geometry, and hence yield displacements.

(v) Nominal yield displacements of components, elements and the system may be readily estimated. This allows the displacement and ductility demand on the system to be quantified. This should ensure that corresponding demands on critical components, particularly those affected by system twist, will not exceed their displacement capacity. This involves a change in traditional design strategies. Instead of estimating the ductility capacity of a system, the designer should locate the critical element and, to protect that element, if necessary, reduce the design ductility demand on the system. The design base shear, based on a much more realistic estimate of the system stiffness, can then be evaluated.

(vi) Global displacement ductility factors, specified in codes for typical structural systems, are inappropriate when the dimensions of components of the system are different. The correlation between the yield displacement of components and the system, overcomes this problem.

(vii) Research is in progress to identify specifically the influence on torsionally restrained and unrestrained mechanisms of the rotary inertia of the mass. The aim is to find a simple, yet rational, approximation to enable this important phenomenon to be incorporated in a routine seismic design procedure.

(viii) The perceived changes in seismic design strategy are in accord with:

(a) the philosophy of capacity design, whereby "the designers should tell the structure what it must do in the event of a major earthquake, rather than ask what it could do",

(b) the adage that, "instead of trying to solve an adverse problem, such as might be generated by torsional phenomena, avoid it!"

\section{ACKNOWLEDGMENTS}

Informal dialogues with Professors A.V. Rutenberg of the Technion Israel Institute of Technology, W.K. Tso of McMaster University, Hamilton, Canada, M.J.N. Priestley of the University of California, San Diego, USA and $H$. Bachmann of the Swiss Federal Institute of Technology, Zürich, have greatly contributed to the clarification of issues, several of which are still considered to be controversial. The generous assistance of Dr A.J.Carr and C. Allington of the University of Canterbury, Dr F. Crisafulli of the National University of Cuyo, Argentina and D. Zamfirescu of the Technical University of Civil Engineering, Bucharest, Romania, who so willingly carried out extensive analytical work, is gratefully acknowledged.

\section{REFERENCES}

1. Study Group on Earthquake Risk Buildings (1996), New Zealand Society for Earthquake Engineering, "The assessment and improvement of the structural performance of earthquake risk buildings", A draft report for general release, pp. 127.

2. Paulay, T. (1996), "Seismic design for torsional response of ductile buildings", Bulletin of the NZ Society for Earthquake Engineering, Vol. 29, No. 3, September, pp. 178-198.

3. Paulay, T. (1997), "A review of code provisions for torsional seismic effects in buildings", Bulletin of the NZ Society for Earthquake Engineering, Vol. 30, No. 3, September, pp. 252-263.

4. Paulay, T. (1998), "Mechanisms of ductile building systems as affected by torsion", Proceedings NZNSEE Technical Conference, Wairakei, pp. 11-118.

5. Paulay, T. (1997), "Displacement-based design approach to earthquake-induced torsion in ductile buildings", Engineering Structures, Vol. 19, No. 9, pp. 699-707.

6. International Association for Earthquake Engineering (1996), "Regulations for seismic design - A world list", Tokyo.

7. Priestley, M.J.N. (1995), "Myths and fallacies in earthquake engineering - Conflicts between design and reality", American Concrete Institute (SP-157), Recent Development in Lateral Force Transfer in Buildings, pp. 231-254.

8. Paulay, T. and Restrepo, J.I. (1998), "Displacement and ductility compatibility in buildings with mixed structural systems", Journal of the New Zealand Structural Engineering Society, Vol. 11, No. 1, pp. 712.

9. Paulay, T. (1998), "A mechanism-based design strategy for torsional seismic response of ductile buildings", European Earthquake Engineering, No. 2, pp. $33-48$ 
10. Paulay, T. (1999), "Some principles relevant to the seismic torsional response of ductile buildings", Proceedings of the second European workshop on the seismic behaviour of Asymmetric and Irregular Structures, Istanbul, Vol. 1, pp. 1-25.

11. Paulay, T. (2000), "A simple displacement compatibility-based design strategy for reinforced concrete buildings", Proceedings of the $12^{\text {th }}$ World Conference on Earthquake Engineering, Auckland, N.Z., CD-ROM paper No. 0062.

12. Standards New Zealand (1992), "Code of practice for general structural design and design loadings for buildings", NZS 4203:1992, Wellington.

13. Park, R. and Paulay, T. (1975), "Reinforced Concrete Structures”, John Wiley \& Sons, New York, pp. 769.

14. Priestley, M.J.N. and Kowalsky, M.J. (1998), "Aspects of drift and ductility capacity of rectangular structural walls", Bulletin of the NZ Society for Earthquake Engineering, Vol. 31, No. 2, June, pp. 73-85.

15. Priestley, M.J.N. (1998) "Brief comments on elastic flexibility of reinforced concrete frames and significance to seismic design", Bulletin of the $N Z$ Society for Earthquake Engineering, Vol. 31, No. 4, December, pp. 246-259.

16. Standards New Zealand (1995), "Concrete Structures Standard, design of concrete structures", NZS 3101:1995, Wellington.

17. Paulay, T. (1997), "Are existing torsional provisions achieving the design aims" Earthquake Spectra, Vol. 13, No. 2, pp. 699-707.
18. Rutenberg, A. (1992), "Nonlinear response of asymmetric building structures; a state of the art review", Nonlinear Seismic Analysis and Design of Reinforced Concrete Buildings, Editors, Fajfar, P. and Krwinkler, H., Elsevier Applied Science, Ansterdam, pp. 281-305.

19. Rutenberg, A., Chandler, A.M., Duan, X.N. and Correnza, J.C. (1995), "Nonlinear seismic response of asymmetric structures: Bibliography, National Building Research Institute, Israel, pp. 21.

20. Paulay, T. (1998), "Torsional mechanisms in ductile building systems", Earthquake Engineering and Structural Dynamics, Vol. 27, pp. 1101-1121.

21. La Llera, J. De. and Chopra, A. (1995), "Understanding of inelastic seismic behaviour of asymmetric-plan buildings", Earthquake Engineering and Structural Dynamics, Vol. 24, pp. 549-572.

22. Dusicka, P. and Davidson, B.J. (1999) "Comparative analyses of the response of single storey torsionally unrestrained ductile systems", Joumal of the Structural Engineering Society New Zealand, Vol. 12, No. 2, September, pp. 13-19.

23. Paulay, T. and Priestley, M.J.N. 1992), "Seismic design of reinforced concrete and masonry buildings", John Wiley \& Sons, New York, pp. 767.

24. Humar, J.L. and Kumar, P. (1999), "Effect of orthogonal inplane structural elements on inelastic torsional response", Earthquake Engineering and Structural Dynamics, Vol. 28, pp. 1071-1097. 